\title{
INCLUSÃO E DIVERSIDADE NA LITERATURA INFANTIL: UM CONTRATO DE COMUNICAÇÃO QUE ESTÁ SAINDO DO ARMÁRIO
}

Anabel Medeiros Azerêdo de Paula ${ }^{1}$

\begin{abstract}
Resumo: Neste artigo, cujo aporte teórico concentra-se na Teoria Semiolinguística (CHARAUDEAU, 2008), pretende-se demonstrar como temas relacionados à homossexualidade são postos em discurso no contrato de comunicação estabelecido pela Literatura Infantil. Nossa hipótese é a de que o leitor destinatário é interpelado por um projeto de influência social, que visa à sua adesão a uma determinada proposta sobre o mundo. Considerando os altos índices de violência contra homossexuais no Brasil, urge a necessidade de combater o preconceito, fomentando o respeito às diferenças. Elegeram-se duas obras remetidas a crianças em estágios diferentes de leitura (COELHO, 2000): Meu amigo Jim (CROWTHER, 2007), destinada a leitores iniciantes, e Meus dois pais (CARRASCO, 2010), indicada a leitores em processo, com a finalidade de descrever as estratégias discursivas, relacionadas à captação, empregadas em dois níveis de leitura distintos. Verifica-se que essas obras possibilitam ao leitor uma atitude projetiva, ligada ao fazer-crer, pois permitem a sua identificação com as personagens e com a trama narrativa e o confronto com as representações que espelham o ser social.
\end{abstract}

Palavras-chave: Literatura Infantil. Homossexualidade. Semiolinguística.

\section{Palavras Iniciais}

É notório o crescimento, nas últimas décadas, da produção contemporânea de livros infantis que abordam temáticas relacionadas a questões sociais, econômicas e até políticas. De acordo com Ramos (2013, p. 302), o tratamento dado a esses temas, considerados difíceis, o gênero e a forma que estruturam obras dessa natureza têm qualificado a Literatura Infantil reconhecidamente como "inclusiva e abrangente".

No entanto, percebe-se que alguns temas difíceis parecem ter sido mais tolerados do que outros no campo literário infantil. Segundo Tatar (1987, apud Evans, 2015), por exemplo, depois que perceberam que suas histórias estavam sendo contadas a crianças, os irmãos Grimms julgaram o sexo como tema inadequado e a violência, não.

Ramos (2009) afirma que a homossexualidade começou a ser trabalhada em livros infantis, a partir de 1980, nos Estados Unidos e nos países nórdicos europeus, como resultado da abertura dessas sociedades às reivindicações de várias minorias. Desde então, a homossexualidade e a família homoparental

\footnotetext{
${ }^{1}$ Mestra em Estudos de Linguagem pela Universidade Federal Fluminense, UFF, Brasil. Doutoranda em Estudos de Linguagem pela Universidade Federal Fluminense, UFF, Brasil.
}

Revista de Letras JUÇARA, Caxias - Maranhão, v. 03, n. 01, p. 249 - 261, ago. 2019 | 249 
começaram a se tornar temas principais e secundários em criações literárias destinadas a crianças e jovens. No Brasil, no entanto, a publicação de obras nacionais que se ocupem dessas temáticas ainda é muito pequena, e a maioria dos livros dessa natureza ainda são traduções de obras estrangeiras. Por isso, podese afirmar, conforme Madalena (2017, p.161), que a produção literária brasileira, nesse segmento, ainda se encontra em uma primeira fase, na qual "predomina o esforço de legitimação e visibilidade em detrimento de uma verdadeira literatura".

Considerando os altos índices de violência contra homossexuais no Brasil, que elevaram o país à primeira posição no ranking de países que mais matam homossexuais no mundo ${ }^{2}$, urge a necessidade de combater, cada vez mais cedo, a homofobia, fomentando o respeito às diferenças e o reconhecimento de que os direitos civis e humanos devem ser usufruídos, igualmente, por todos os cidadãos. Por isso, decidiu-se investigar como os temas fraturantes, homoafetividade e homoparentalidade, são postos em discurso na Literatura Infantil. A partir de uma análise discursiva de viés semiolinguista (CHARAUDEAU, 2008), pretende-se explicitar as propostas interlocutórias (PAULINO, 2000) e as visadas discursivas (CHARAUDEAU, 2004) de duas obras infantis que abordam essas temáticas, nomeadamente, Meus dois pais (CARRASCO, 2010) e Meu amigo Jim (CROWTHER, 2007).

\section{O contrato de comunicação estabelecido pela Literatura Infantil}

O contrato de comunicação para a Teoria Semiolinguística (CHARAUDEAU, 2008), em geral, envolve quatro sujeitos, nomeadamente, comunicante e enunciador, no polo de produção; destinatário e interpretante, no polo de recepção. Vale destacar que a Semiolinguística concebe o sujeito como uma categoria do discurso, que pode ser ocupada por um ou mais indivíduos na situação de comunicação.

No contrato de comunicação que se realiza no livro infantil, cujo modo de organização discursivo predominante é o narrativo, o sujeito comunicante é preenchido por uma gama de profissionais envolvidos na produção da obra, a

2 De acordo com o relatório publicado pelo Grupo Gay da Bahia, disponível em: https://homofobiamata.files.wordpress.com/2019/01/relatorio-2018-1.pdf. Acesso em abr. de 2019.

Revista de Letras JUÇARA, Caxias - Maranhão, v. 03, n. 01, p. 249 - 261, ago. 2019 | 250 
saber: o escritor, o ilustrador, o designer gráfico, o editor etc. O sujeito enunciador atua em um circuito interno e, nesse contrato, é ocupado pelo narrador, que atua tanto na parte verbal quanto na parte visual do texto. Ainda no circuito interno, mas no polo de recepção, está o sujeito destinatário, compreendido como a imagem que o narrador produz do público leitor. Já na parte externa, está o sujeito interpretante ou, em termos desse contrato, o leitor real. A produção literária de temáticas fraturantes como a homoafetividade e a homoparentalidade tem de se submeter a critérios não-literários para alcançar as prateleiras de livrarias e bibliotecas, por isso, pode-se afirmar que uma obra dessa natureza seja produzida não só pelo escritor, mas também pelos interesses do editor que publica e comercializa o livro, ou seja, por uma instância de produção.

Como o escritor, enquanto representante dessa instância de produção, não sabe por quem seu livro será lido, para lograr êxito em seu projeto de escritura, deve pressupor as características do indivíduo que ocupará a posição de leitor real de sua obra. Então, produz uma imagem desse sujeito, a que se denomina leitor destinatário. Desse modo, um indivíduo pode ou não se tornar o leitor real de uma obra, para isso precisa ter atributos compatíveis com os do destinatário inscrito nela.

Em obras que abordam temas fraturantes, a criança não possui o monopólio nem do papel de leitor destinatário, nem do papel de leitor real na Literatura Infantil, embora ocupe primordialmente essas duas funções. Adultos também podem se tornar leitores reais de obras infantis, pois há uma dupla audiência inscrita em livros infantis, o que faz com que algumas estratégias discursivas sejam dirigidas, especificamente, a adultos.

Embora o sujeito destinatário do contrato de comunicação em livros ilustrados infantis seja constituído, prioritariamente, pela criança, a presença do adulto nessa mesma posição pode ser significativa para influenciar a abordagem temática que se faz nessas obras, principalmente, no que tange aos temas fraturantes como a homossexualidade e a homoafetividade, pois, uma vez que um indivíduo adulto torna-se o leitor real de uma obra, ele pode incentivar ou impedir que a criança tenha acesso a ela.

Em se tratando de obras que abordam temas desafiadores, Evans (2015) afirma que muitos escritores, ilustradores e pesquisadores já se pronunciaram 
sobre o controle que os adultos tentam exercer sobre o que as crianças leem, como o escritor e ilustrador alemão Erlbrush (2006, apud EVANS, 2015, p.8), por exemplo, quando declara que nenhuma criança é ignorante, no sentido de não ser capaz de interpretar e compreender o sentido de uma obra. Para ele, esse é o modo como os adultos gostam de pensar, já que eles gostam de impor arestas a elas.

Entretanto, percebe-se que 0 adulto exerce influência intensa neste contrato, ao atuar como leitor destinatário, pois é nessa função que a instância de produção concentra a sua atenção para produzir uma obra que, por um lado, agrade à criança e, por outro, não desagrade ao adulto. Para fins didáticos, elaborou-se um esquema que demonstra como ocorre o contrato de comunicação na leitura dessas obras:

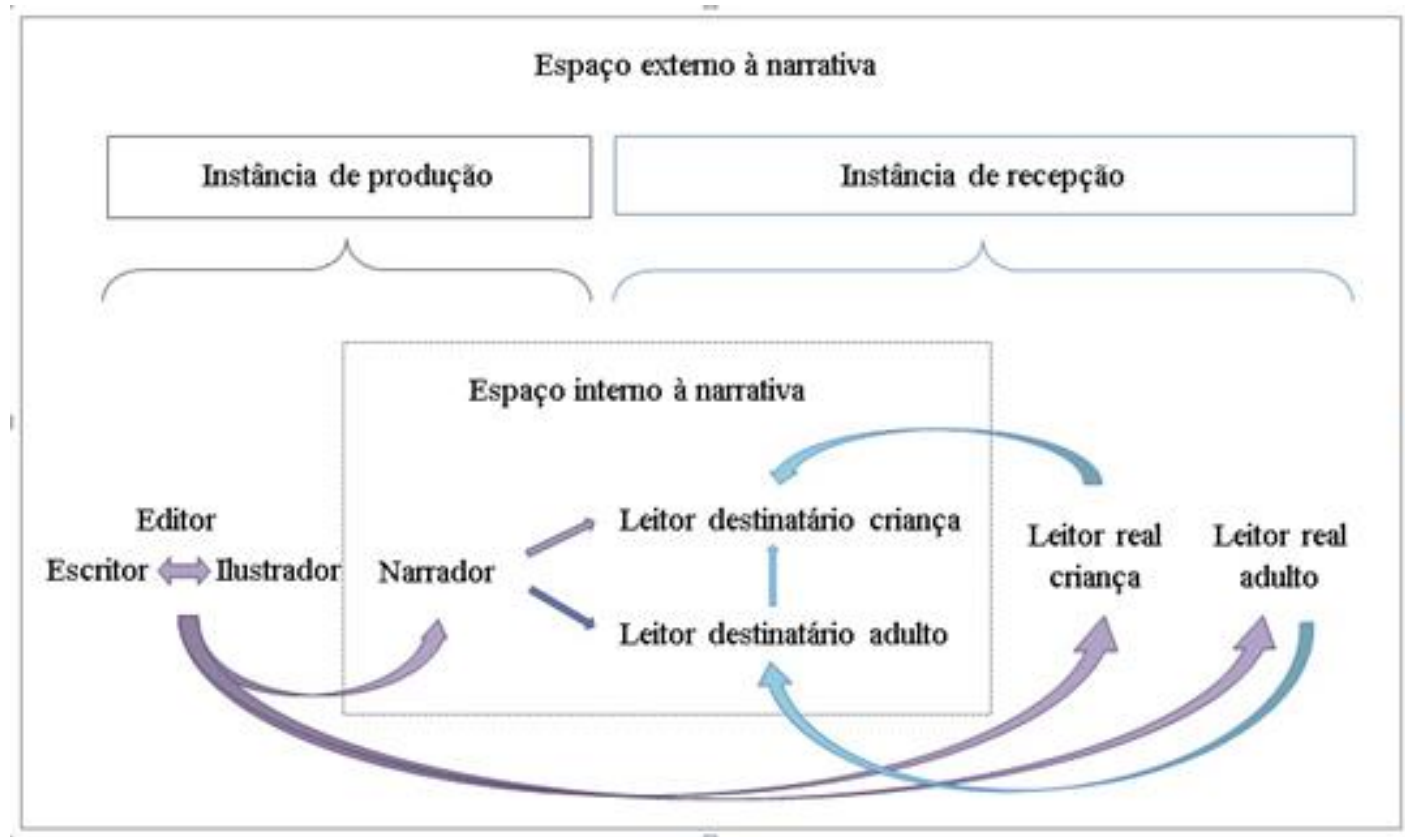

De acordo com a semiolinguística, toda interação comunicativa é motivada por uma intenção psicossociodiscursiva, que corresponde à finalidade do ato de linguagem. Dessa forma, todo ato de linguagem apresenta uma ou mais visadas, que são produzidas a partir da relação de força que o enunciador exerce sobre 0 destinatário e também da posição que o sujeito enunciador prevê para o destinatário ocupar na troca linguageira. Desse modo, Charaudeau (2004) descreveu, inicialmente, seis visadas, a saber: informação, incitação, solicitação, prescrição, instrução e demonstração. Para os fins dessa análise, somente as 
visadas de incitação e de prescrição serão tomadas, pois nesses e em diversos contratos estabelecidos com a criança, verifica-se que essas são as visadas, geralmente, mais selecionadas. Na visada de incitação, o sujeito enunciador deseja mandar-fazer, mas, como não possui autoridade para tal, precisa persuadir ou seduzir o seu destinatário, que, por sua vez, encontra-se em posição de dever acreditar. Na visada de prescrição, o sujeito enunciador, autorizado, quer mandar fazer e, portanto, o sujeito destinatário deve-saber.

A Literatura Infantil sempre esteve atravessada por uma finalidade formativa, por isso, é muito recorrente haver objetivos ligados à visada de prescrição em histórias infantis. No entanto, em se tratando da abordagem de temáticas fraturantes como a homossexualidade e a homoafetividade, tendo como objetivo fomentar a aceitação e o respeito às diferenças, é preciso convencer o leitor destinatário quanto à legitimidade dessas realidades, antes de the propor atitudes e comportamentos desejáveis.

\section{A Literatura Infantil e as propostas de interlocução}

De acordo com Coelho (2000), desde o nascimento da Literatura Infantil, há aqueles que acreditam que esse tipo de literatura deva servir a fins eminentemente artísticos, sem compromisso com a realidade e com os valores ético-sociais vigentes. Nesse caso, pressupõe-se que as obras infantis devam apresentar, predominantemente, objetivos correspondentes a uma visada de incitação, como, por exemplo, estimular a imaginação e a criatividade. Contudo, a autora pontua que há, também, outras pessoas que consideram ser o papel da Literatura Infantil o de ajudar a criança a se integrar à sociedade, reproduzindo e perpetuando suas crenças, o que implicaria em propósitos relacionados a uma visada de prescrição, como ensinar um comportamento determinado ou transmitir um costume.

Palo e Oliveira (2001) acreditam que a Literatura Infantil foi idealizada para cumprir uma função utilitário-pedagógica. Desse modo, a visada predominante na Literatura Infantil seria a de prescrição, cujos objetivos poderiam ser: orientar, preparar, formar a criança. Para essas autoras, esse encargo é reforçado pela representação social com a qual a criança é compreendida no ocidente: um ser em 
formação, sem autonomia, submisso ao adulto. Este, sim, seria o ser detentor de saberes, conhecimentos e experiências, que estaria autorizado a tutelar a criança. Dessa forma, segundo as autoras, reproduz-se a estrutura social capitalista, em que se verifica a sobreposição do dominador ao dominado.

Com o objetivo de identificar o propósito preponderante no texto, Paulino (2000) distinguiu três grandes tendências, pelas quais a instância de produção apresenta a sua proposta de interlocução com o leitor, a saber:

- $\quad$ Proposta Pragmática - trata-se de um tipo de narrativa condutora de comportamentos, que se propõe interferir na vida dos destinatários, de modo direto.

- Proposta ficcional - intenta agenciar o imaginário dos leitores/espectadores. Entretanto, a imaginação que se desenvolve na interação ficcional tem caráter específico. [...] Os elementos da narrativa de ficção adquirem outra natureza, diferente da que tinham anteriormente, pois se tornam signos articulados para uma produção de mundos. [...] a narrativa ficcional é detonadora desse jogo de significações que excita o imaginário a participar de possibilidades da composição de outros mundos.

- Proposta informativa - intenta envolver intelectualmente o leitor, ouvinte, espectador no acesso/produção simbólicos de conhecimentos, que podem ser científicos, sociais e de outras naturezas. Narrar para que o outro fique sabendo é a proposta básica desse tipo de narrativa. (PAULINO, 2000, p. 43-45)

Conforme Paulino (2000) destaca, essas são propostas de interação básicas, que podem aliar-se a outras para compor uma narrativa. Entretanto, parece cada vez mais difícil, para o analista, distinguir a proposta de interação dominante em obras infantis, já que esse segmento de produção literária apresenta obras que, além de divertir, emocionar e dar prazer também ensinam modos de ver o mundo, viver, pensar, reagir e criar (RAMOS; FONSECA, 2015).

\section{Breve análise de figurações da homossexualidade e da homoparentalidade}

Em Meus dois pais (CARRASCO, 2010), é possível classificar a proposta interlocutória predominante na obra como pragmática, uma vez que, em nota, ao fim do livro, o escritor sugere uma mudança de comportamento ao leitor, ao afirmar que é preciso conversar sobre a homossexualidade para entender que alguém pode ser diferente sem ser errado. Para alcançar esse fim, Carrasco (2010) 
seleciona, pelo menos, duas visadas, uma de incitação e outra de prescrição. $\mathrm{O}$ escritor visa incitar o leitor a aceitar a homossexualidade, por meio de uma estratégia de captação altamente patêmica para aqueles classificados como leitores em processo. $O$ escritor seleciona, como intriga para sua narrativa, um momento conflituoso na vida de uma criança, a descoberta da homossexualidade de seu pai, apresentando uma narrativa linear, composta por início, meio e fim. A proposta pragmática de Carrasco (2010) também está ligada a uma visada de prescrição, pois recomenda o comportamento ético de aceite e de respeito à homossexualidade dentro do próprio texto, na fala de uma das personagens, neste caso, a mãe do menino Naldo, e no peritexto já mencionado, dirigido ao leitor ao fim do livro.

Naldo é o protagonista dessa história e um narrador autodiegético ${ }^{3}$, que inicia seu relato afirmando que, apesar de ter ficado triste com a separação de seus pais, sentia-se aliviado por não ter mais de vê-los brigando. O menino declara ainda que gostava muito de passar os fins-de-semana com o pai, principalmente, depois da chegada de Celso, um amigo que passou a morar com ele. Assim que Naldo se muda, fica confuso com o fato de os dois dormirem no mesmo quarto. No entanto, infere-se que esse costume, incomum na amizade entre dois homens, parece ter deixado de ser uma ideia estranha ao menino e não influenciava a convivência entre os três, pois não há nenhuma menção a conflitos decorrentes dessa situação.

Antes que Celso e o pai de Naldo fossem identificados pelo menino como homossexuais, a relação familiar entre os três era agradável: "Eu sentia falta da mamãe, é claro. Mas a vida estava muito boa com os dois cuidando de mim" (CARRASCO, 2010, p.19); e até superava a de outras famílias: "Alguns dos meus colegas ficavam chateados porque os pais não estavam nem aí para as reuniões. Mas o papai e o Celso queriam saber de tudo o que acontecia comigo na escola, então foram à reunião" (CARRASCO, 2010, p.20).

Quando Naldo ouve de seus amigos que seu pai é gay, o garoto desloca a representação positiva que tinha feito a respeito da relação entre Celso e o pai para uma pejorativa, rejeitada socialmente. No momento em que os dois homens são categorizados como homossexuais, o menino ainda questiona a incompatibilidade

\footnotetext{
${ }^{3}$ Classificação dada ao narrador que é co-referencial com o protagonista da história (cf. AGUIAR E SILVA, 1982).
}

Revista de Letras JUÇARA, Caxias - Maranhão, v. 03, n. 01, p. 249 - 261, ago. 2019 | 255 
entre as características pessoais do pai e de Celso com as representações sociais de quem é gay:

- O papai tinha sido casado. Como podia ser gay?

- Mas por que justo meu pai tem que ser diferente?

- Mas o meu pai não é delicado, nem o Celso! (CARRASCO, 2010, pp.2230).

Mesmo constatando incongruências, o menino sucumbe aos estereótipos e se recusa a continuar vivendo com o casal, passando a morar com a avó, onde não lhe é prestada a mesma atenção. Com isso, verifica-se o que Foucault (1988) afirma sobre as sexualidades periféricas, quando, no século XIX, houve incorporação das perversões e nova especificação dos indivíduos, transformando o homossexual, que outrora era visto como um sodomita reincidente, em um personagem.

Nada daquilo que ele é, no fim das contas, escapa à sua sexualidade. Ela está presente nele todo: subjacente a todas as suas condutas, já que ela é o princípio insidioso e infinitamente ativo das mesmas; inscrita sem pudor na sua face e no seu corpo já que é um segredo que se trai sempre. É-lhe consubstancial, não tanto como pecado habitual, porém como natureza singular (FOUCAULT, 1988, p.43).

Essa ideia está implicitamente metaforizada na explicação que a mãe de Naldo usa para responder o questionamento do filho:

\footnotetext{
- Mas por que justo meu pai tem que ser diferente?

$\mathrm{Na}$ mesa ainda havia uma bandeja de doces. A mamãe pegou um de chocolate e outro de amêndoas.

- Olhe esses doces. Ambos são doces, mas diferentes entre si. Não é errado ser diferente! Imagine se todo mundo tivesse cabelo igual, nariz igual, rosto igual? Jeito de ser igual? (CARRASCO, 2010, p.30).
}

O que a mãe de Naldo quer mostrar ao menino é que as pessoas podem distinguir-se umas das outras por características físicas e psicológicas. No entanto, ao afirmar que não é errado ser diferente, infere-se que a mãe do menino esteja se referindo à orientação sexual do ex-marido, a qual é dissonante de um padrão convencionado. Ao distinguir um indivíduo pela sua orientação sexual, atribui-se à homossexualidade a causa de todas as características do sujeito. Por outro lado, 
em se tratando de heterossexualidade, não se costuma relacionar as qualidades do sujeito heterossexual à sua orientação sexual.

Em Meu amigo Jim (CROWTHER, 2007), a proposta interlocutória preponderante é a ficcional, pois a partir da rejeição, vivida por Jack na aldeia das gaivotas, o leitor é levado a desejar um mundo mais receptivo para a convivência dos pássaros que, embora pertencentes a espécies distintas, possuem em comum o amor que sentem um pelo outro.

Jack e Jim são um melro negro e uma gaivota branca, respectivamente, que se conhecem por obra do acaso, na beira de uma praia. Os dois pássaros tornam-se amigos e passam algum tempo juntos. Jim gosta tanto de estar com Jack que o convida para morar consigo, mas Jack não é bem recebido na aldeia de Jim. Só depois que o melro descobre um baú de histórias na casa do amigo e começa a lê-las para as gaivotas que não sabiam ler, é que o pássaro negro conquista a simpatia e a confiança dos pássaros brancos da aldeia.

A proposta ficcional dessa narrativa também parece selecionar uma visada de incitação, mas para levar o leitor a crer que dois seres diferentes podem conviver em harmonia. Nessa obra, percebe-se, com bastante clareza, que essa visada destina-se a combater o preconceito racial, já que Jack é um pássaro negro e Jim, branco. No entanto, pode-se afirmar que essa visada de incitação também está atrelada à luta contra a discriminação da homoafetividade, pois Jack e Jim são dois pássaros machos que passam a viver na mesma casa e, inclusive, a dormir na mesma cama. Como o tratamento do preconceito racial excede o limite temático proposto para esta análise, será abordado apenas o tema relacionado à homossexualidade, que parece manifestar-se de modo mais opaco nessa obra, principalmente, na versão brasileira que traduziu o título original Jack and Jim por Meu amigo Jim, o que pode contribuir para que a homoafetividade não seja contemplada, ainda no processo de pré-leitura, como uma das hipóteses de relacionamento entre os dois pássaros.

Endereçada prioritariamente a leitores iniciantes, Meu amigo Jim (CROWTHER, 2007) apresenta personagens animais antropomorfizados em uma narrativa linear, composta por início, meio e fim. Apesar de o melro e a gaivota serem animais de pequeno porte, o que poderia ser um fator de identificação entre eles e as crianças, Jim e Jack parecem ser dois jovens machos solteiros. Essa 
distinção é facilmente reconhecida por meio da vestimenta dos personagens protagonistas e de todos os outros que habitam a aldeia de Jim. Conforme Nikolajeva e Scott (2011) afirmam, a caracterização por meio das roupas é de grande importância para comunicar informações relacionadas ao gênero, à idade e à condição social desses personagens.

Por último, vale destacar dois efeitos de sentidos importantes que a imposição da leitura como a habilidade diferencial de Jack pode causar. O primeiro refere-se à aceitação do melro pelas gaivotas, e o segundo relaciona a falta de leitura a um comportamento preconceituoso. Como assinalado anteriormente, Jack foi bem quisto na comunidade depois que passou a ler todas as noites para as gaivotas, ou seja, ele só foi aceito por ter uma habilidade que faltava aos outros. $\mathrm{O}$ aceite da convivência se deu, portanto, por uma questão de interesse coletivo e não pelo respeito à dignidade do ser. Em relação à atitude discriminatória das gaivotas, pode-se inferir que foi o acesso à leitura que as tornaram seres tolerantes, o que parece estabelecer uma relação de causa e efeito entre a falta de leitura e o preconceito. Isso pode trazer implicações não correspondentes às motivações que permeiam a discriminação na sociedade em que se vive.

\section{Considerações Finais}

As obras selecionadas para esta análise demonstram como uma intencionalidade argumentativa pode estar implícita em uma narrativa endereçada a crianças. À Literatura Infantil sempre foi solicitado o cumprimento de um propósito formativo, que disseminasse os valores éticos requeridos à convivência social harmônica. Apesar de essa concepção já ser aceita entre os estudiosos, percebese que, por meio da Literatura Infantil, para além dos objetivos educativos, pode-se promover um processo de espelhamento social entre a criança e as representações que lhe são expostas nos livros, capaz de fazê-la refletir sobre a situação-problema abordada na obra.

A obra de Carrasco (2010), por exemplo, recria um universo fictício altamente verossímil e patêmico o suficiente para comover o leitor criança e fazêlo perceber como as representações sociais estereotipadas e depreciativas, consolidadas na sociedade contemporânea a respeito da homossexualidade, 
trazem sofrimento ao homossexual e à sua família. Em relação à materialidade do texto, a obra parece produzir um efeito impactante no público leitor não só por retratar uma intriga conflituosa, mas também pelo apelo visual das ilustrações, que recobrem a totalidade das páginas, por vezes, apresentando uma cena em páginas duplas, fazendo uso simbólico de cores e de outras técnicas artísticas bastante sofisticadas para estabelecer relações de natureza semântica com a parcela verbal do texto.

Já a obra de Crowther (2007) faz uso de personagens animais como estratégia de captação de crianças ainda em fase iniciante de leitura e apresenta as temáticas, relacionadas a preconceitos, a partir de uma intriga bastante acessível ao imaginário sociodiscursivo da criança. Percebe-se que a temática racismo é mais transparente que a homofobia nessa obra, mas a abordagem da homoafetividade faz-se sugestiva na efabulação da história, tanto na parte verbal, quando Jack assume gostar de Jim, quanto na parte visual, que mostra os dois pássaros, dormindo na mesma cama.

A cobertura figurativa dada, tanto ao conflito pelo qual Naldo e seu pai passam quanto a que retrata o que Jack e Jim têm de enfrentar para ficarem juntos, reforça o efeito patêmico das visadas de incitação nas obras, pois, ao sensibilizar o leitor, permitem a sua projeção à narrativa e a empatia com as personagens da história. Com isso, o leitor pode experimentar os (dis)sabores da rejeição e do preconceito, provados não só pelos personagens homossexuais, mas também pelas pessoas mais próximas de $\mathrm{si}$, e as narrativas podem alcançar a finalidade que almejam.

No entanto, como se pode presumir, livros como esses ainda não são selecionados para compor as listas de leituras escolares, seja por serem julgados inadequados para as crianças, seja por serem considerados desafiadores para os mediadores. Consequentemente, limita-se a possibilidade de expressão e de conscientização, intrínseca à literatura, propícia para a humanização dos indivíduos. 


\title{
INCLUSION AND DIVERSITY IN CHILDREN'S LITERATURE, A CONTRACT OF COMMUNICATION THAT IS COMING OUT OF THE CLOSET
}

\begin{abstract}
In this paper, based on the Semiolinguistic Theory (CHARAUDEAU, 2008), it is intended to demonstrate how themes related to homosexuality are put into discourse in some contracts of communication established in Children's Literature. Our hypothesis is that the target reader is approached by a social influence project, which aims at his/her adherence to a certain proposal about the world. Considering the high rates of violence against homosexuals in Brazil, there is an urgent need to combat prejudice, encouraging respect for differences. Two Children books indicated to readers in different stages of reading (COELHO, 2000) were selected: Meu amigo Jim (CROWTHER, 2007), for beginning readers, and Meus dois pais (CARRASCO, 2010), for readers in process, in order to describe the discursive strategies, related to captation, used in two different levels of reading. It is verified that these books offer a projective attitude to the reader, related to make believe, because they allow their identification with the characters and with the narrative plot, and also the confrontation with the representations of the social being.
\end{abstract}

Keywords: Children's Literature. Homosexuality. Semiolinguistics.

\section{Referências}

AGUIAR E SILVA, Vítor Manuel de. Teoria da Literatura. Coimbra: Almedina, 1982.

CARRASCO, Walcyr. Meus dois pais. Ilustrador: Laurent Cardon. São Paulo: Ática, 2010.

CHARAUDEAU, Patrick. Visadas discursivas, gêneros situacionais e construção textual. In: Machado, Ida Lúcia et al. (orgs). Gêneros: reflexões em Análise do Discurso. Belo Horizonte: FALE/UFMG, 2004, p. 13-42.

. Linguagem e discurso: Modos de organização. São Paulo: Contexto, 2008. COELHO, Nelly. Literatura Infantil: teoria, análise, didática. São Paulo: Moderna, 2000.

CROWTHER, Kitty. Meu amigo Jim. Tradução Flávia Varella. São Paulo: Cosac Naify, 2007.

EVANS, Janet. Challenging and controversial picturebooks: creative and critical responses to visual texts. Edited by Janet Evans. London: Routledge, 2015.

FOUCAULT, Michel. A história da sexualidade I - A vontade de saber. Tradução Maria Thereza da Costa Albuquerque e J. A. Guilhon Albuquerque. 10ª ed. Rio de Janeiro: Edições Graal, 1988.

MADALENA, Emanuel. Temáticas Transgênero na Literatura Infantil. Elos. Revista de Literatura Infantil e Xuvenil, 4, 2017, pp. 159-178.

NIKOLAJEVA, Maria; SCOTT, Carole. Livro ilustrado: palavras e imagens. Tradução Cid Knipel. São Paulo, Cosac Naify, 2011.

PALO, Maria José ; OLIVEIRA, Maria Rosa. Literatura Infantil - voz de criança. $3^{a}$ ed. Série Princípios. Rio de Janeiro: Ática, 2001. 
PAULINO, Graça. Diversidade das narrativas. In: Paiva, Aparecida et al. (orgs.). No fim do século: a diversidade - o jogo infantil e juvenil. Belo Horizonte, MG: Autêntica, 2000, p.39-48.

RAMOS, Ana Margarida. Saindo do Armário - Literatura para a infância e a reescrita da homossexualidade. Forma Breve, Aveiro, n. 7, 2009, p. 295 - 314.

As famílias não tradicionais na literatura para a infância e a juventude: a representação da homoparentalidade, in: Ramos, Ana Margarida et al. (ed.). A família na literatura infantil e juvenil. CD room. Universidade do Minho. Portugal, 2013, p.301-317.

; FONSECA, Ana Daniela. Tendências da literatura juvenil contemporânea: os temas fraturantes na obra de Ana Saldanha. Literartes. São Paulo, n. 4, 2015, pp. $89-106$.

Data de Submissão:16/04/2019

Data de Aprovação: 04/06/2019

Revista de Letras JUÇARA, Caxias - Maranhão, v. 03, n. 01, p. 249 - 261, ago. 2019 | 261 